\title{
A rare cause of dysphagia: hairy esophagus
}

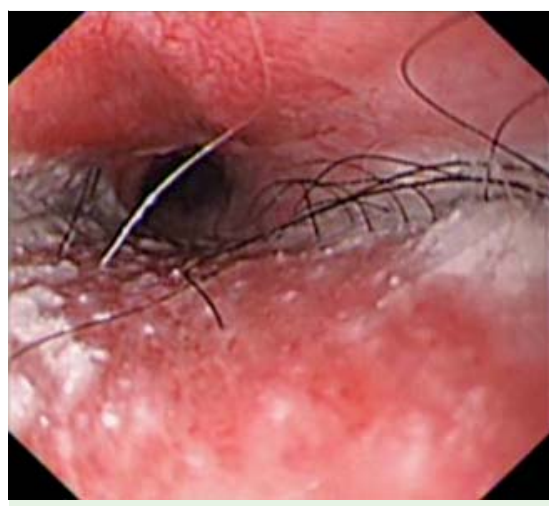

Fig. 1 Esophageal endoscopic view in a 61year-old man with progressive dysphagia, showing the intact skin graft in the proximal esophagus with the epithelial surface bearing hair.

A 61-year-old man was admitted to our clinic due to progressive dysphagia over the past 4 weeks. He had a history of laryngeal cancer. After failure of radiation therapy 9 months previously, total laryngectomy and bilaterally selective neck dissection had been carried out. Pectoralis major myocutaneous flap reconstruction resulted in the postoperative complication pharyngocutaneous fistula, 3 months after the operation. Esophageal endoscopic examination revealed an intact skin graft in the hypopharynx and proximal esophagus, with the epithelial surface bearing hair, as well as a proximal esophageal stricture ( Fig.1). Apart from the flap, cervical computed tomography revealed no pathological concerns
(- Fig.2). Endoscopic dilation of the stricture resulted in improvement of symptoms.

Current treatment of laryngeal and pharyngeal tumors involves a combination of radiation therapy, chemotherapy, and radical surgical resection. With extensive surgical resection, deltopectoral or pectoralis major flaps are frequently used to restore/reconstruct both the anatomy and function of the operative area $[1,2]$. The reconstructed tube is formed by rotating the skin flap, with the flap placed in the cervical region with the raw surface on the spine and the skin turned on itself, so that the outer epithelial surface becomes the inner lining. However, the epithelial surfaces of flaps may bear hair, particularly in males, and may result in a "hairy esophagus" [3], which further could give rise to the sensation of dysphagia.

Although hair growth has been reported to cease spontaneously within 6-12 months of surgery, on rare occasions it may persist. Where the hair growth in the endopharynx-esophagus is exuberant, patients present with progressive dysphagia, hair-spitting, and choking episodes due to the masses of hair [3]. The endoscopic solution is complex, and bougienage dilatation and hair removal using forceps and/or scissors have been reported $[3,4]$. Radiation therapy has been used to treat secondary dysphagia due to excessive hair growth $[2,3]$.

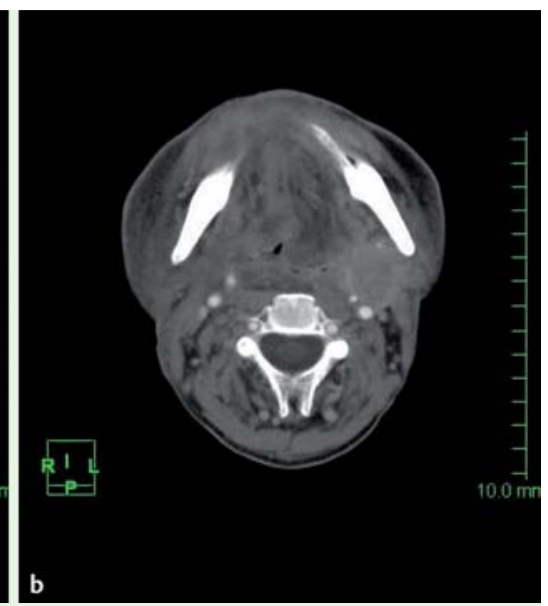

Fig. 2 Sagittal (a) and horizontal (b) cervical computed tomography scans showing nothing of note apart from the myocutaneous flap.
Endoscopy_UCTN_Code_CCL_1AB_2AC_3AH

\section{Competing interests: None}

\section{H. Korkmaz ${ }^{1}$, Ç. Elsürer ${ }^{2}$, T. Temel ${ }^{3}$}

${ }^{1}$ Selcuk University, Faculty of Medicine, Departments of Internal Medicine, Division of Gastroenterohepatology, Selcuklu, Konya, Turkey

2 Selcuk University, Faculty of Medicine, Department of Otorhinolaryngology, Selcuklu, Konya, Turkey

${ }^{3}$ Eskisehir Osmangazi University, Faculty of Medicine, Department of Internal Medicine, Division of Gastroenterology, Eskisehir/Turkey

\section{References}

1 Piazza C, Tglietti V, Nicolai P. Reconstructive options after total laryngectomy with subtotal or circumferential hypopharyngectomy and cervical esophagectomy. Curr Opin Otolaryngol Head Neck Surg 2012; 20 : 77-88

2 Agha FP, Wimbish KJ. Hirsute esophagus: Clinical and roentgen features. Gastroenterol Radiol 1984; 9: 297-300

3 McLean Gl, Laufer I. "Hairy esophagus." A complication of pharyngo-esophageal reconstructive surgery in two cases. Am J Radiol 1979; 132: 269-270

4 Perez LC, Fernandes MR, Aguilera XAC et al. Hairy esophagus: A complication of pharyngo-esophageal reconstructive surgery. Rev Esp Enferm Dig 2008; 100: 294-295

\section{Bibliography}

DOI http://dx.doi.org/

10.1055/s-0033-1344572

Endoscopy 2013; 45: E321

(c) Georg Thieme Verlag KG

Stuttgart · New York

ISSN 0013-726X

\section{Corresponding author}

\section{H. Korkmaz}

Selcuk Üniversitesi

Selçuklu Tıp Fak

Alaeddin Keykubad Kampusü

42075 Selçuklu

Konya

Turkey

Fax: +332-241-6065

husein68@hotmail.com 